This item was submitted to Loughborough's Research Repository by the author.

Items in Figshare are protected by copyright, with all rights reserved, unless otherwise indicated.

\title{
An efficient approach to the synthesis of novel pyrene-fused azaacenes
}

PLEASE CITE THE PUBLISHED VERSION

http://dx.doi.org/10.1021/ol401438a

\section{PUBLISHER}

(c) American Chemical Society

\section{VERSION}

AM (Accepted Manuscript)

\section{PUBLISHER STATEMENT}

This work is made available according to the conditions of the Creative Commons Attribution-NonCommercialNoDerivatives 4.0 International (CC BY-NC-ND 4.0) licence. Full details of this licence are available at: https://creativecommons.org/licenses/by-nc-nd/4.0/

\section{LICENCE}

CC BY-NC-ND 4.0

\section{REPOSITORY RECORD}

Feng, Xing, Fumitaka Iwanaga, Jian-Yong Hu, Hirotsugu Tomiyasu, Masahiro Nakano, Carl Redshaw, Mark R.J. Elsegood, and Takehiko Yamato. 2019. "An Efficient Approach to the Synthesis of Novel Pyrene-fused Azaacenes”. figshare. https://hdl.handle.net/2134/18263. 


\title{
An Efficient Approach to the Synthesis of Novel Pyrene-Fused Azaacenes
}

\author{
Xing Feng, ${ }^{\dagger}$ Fumitaka Iwanaga, ${ }^{\dagger}$ Jian-Yong $\mathrm{Hu}_{,}{ }^{,+,+\neq}$Hirotsugu \\ Tomiyasu, ${ }^{\dagger}$ Masahiro Nakano, ${ }^{\ddagger}$ Carl Redshaw, ${ }^{\sharp}$ Mark R. J. \\ Elsegood, ${ }^{\S}$ and Takehiko Yamato ${ }^{*}{ }^{\dagger}$
}

Department of Applied Chemistry, Faculty of Science and Engineering, Saga University, Honjo-machi 1, Saga-shi, Saga, 840-8502, Japan, and Emergent Molecular

Function Research Group, RIKEN Center for Emergent Matter Science (CEMS), Wako, Saitama, 351-0198, Japan, and Department of Chemistry, The University of Hull, Hull, HU6 7RX, U. K., and Chemistry Department, Loughborough University, Leicestershire, LE11 3TU, U. K.

yamatot@cc.saga-u.ac.jp; jian-yong.hu@riken.jp

Received Date (will be automatically inserted after manuscript is accepted)

\section{ABSTRACT}

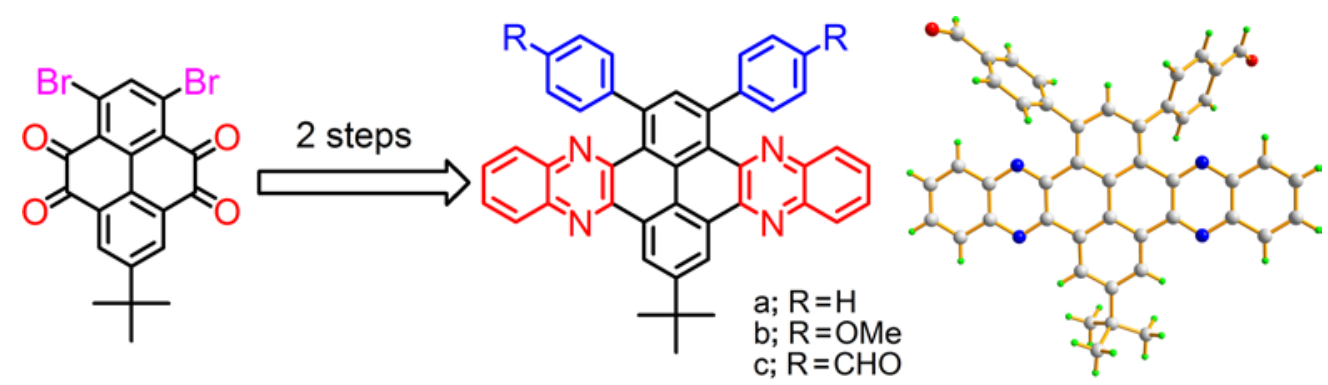

An efficient synthetic approach for functionalization of both the active sites (1,3-) and the K-region (4,5,9,10-) of pyrene was accomplished by bromination and oxidation with considerable yield. These novel pyrene-fused azaacenes were thoroughly investigated by X-ray diffraction studies, electrochemistry and DFT calculations.

The rational design and synthesis of organic $\pi$ conjugated molecules with potential applications in electronics and optoelectronics (e.g. organic light-emitting diodes (OLEDs), organic field-effect transistors (OFETs) and organic photovoltaics (OPVs), etc.) has been the focus of much attention. ${ }^{1,2}$ n-Acenes show excellent charge mobilities and lower band-gap with increasing numbers of fused rings. ${ }^{3}$ However, the stability and solubility of the higher acenes $(n>5)$ also gradually decrease, and those make their applications somewhat limited. Only a few examples of higher acenes $(5 \leq n \leq 9)$ have been synthesized and isolated, and in some cases stable derivatives are known. ${ }^{4,5}$ On the other hand, the properties of polycyclic aromatic hydrocarbons (PAHs) depend on their molecular sizes and structures. ${ }^{6}$ An example is the system reported by Wudl et al., who introduced a non-propeller twisted topology, and found that strategically located phenyl substituents greatly improved the stability of heptacene for the preparation of light-emitting diodes. ${ }^{7}$ Another approach is the replacement of the $\mathrm{CH}$ moieties by nitrogen atoms in PAHs, which can also enhance the stability.

Azaacenes are formed by using imine nitrogen atoms $(-\mathrm{N}=)$ in the place of the $\mathrm{CH}$ group of acenes, and have been shown to possess enhanced electron affinity, high stability and good solubility with less negative reduction potential (compared to acenes), not only by experiment, but also by theoretical investigations. ${ }^{2}$ The electron affinity of the resultant compounds is noticeably higher than those of analogous PAHs, which are promising candidates for n-type organic semiconductors. ${ }^{8,9}$ 


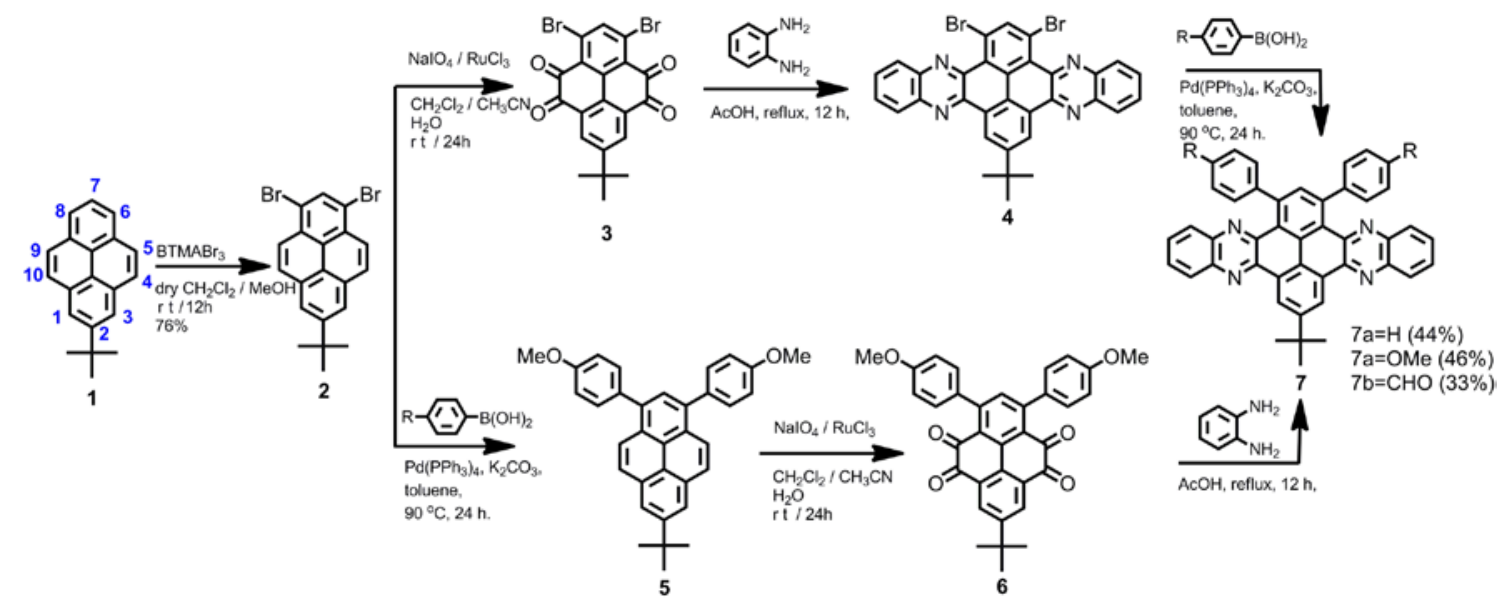

Scheme 1 . The synthetic routes for the preparation of $7, \mathrm{BTMABr}_{3}=$ benzyltrimethylammonium tribromide

Pyrene is a classical member of the family of PAHs, and possesses high thermal stability, photoluminescence efficiency, and enhanced hole-injection ability. Much recent efforts have been devoted to the synthesis of pyrene-based materials for organic electronics. ${ }^{10}$ There are two strategies to effectively functionalize the pyrene core to control geometry. One way is direct electrophilic substitution of the pyrene at the active sites, namely, 1-, 3, 6-, and 8-positions, or directly to attack at the 4-, 5-, 9and 10-positions by employing sterically bulky tert-butyl groups at the 2- and 7-positions. ${ }^{10}$ Recently, our group has reported a novel 1,3,5,9-tetrabromo-7-tert-butylpyrene; ${ }^{11}$ bromopyrenes are pivotal intermediates for functionalizing the pyrene core by Suzuki/Sonogashira cross-coupling reactions or nucleophilic substitution. ${ }^{10}$ The resulting substitution compounds can effectively avoid passive aggregations, which allow them to be used as emitters in OLEDs. ${ }^{12}$ Another strategy is to oxidize the K-region of the pyrene by using ruthenium chloride as a catalyst. ${ }^{13}$ This involves expansion of the conjugation of the linear aromatic backbone using additional aromatic rings via condensation reactions with diamines; in the case of N-PAHs this occurs in surprisingly good yields. ${ }^{14,15}$ N-PAHs type structures exhibit planar conformations, which result in larger delocalization of electrons with higher charge carrier abilities and lower energy band-gap, as required in n-type organic semiconductors. ${ }^{2}$ It is also noteworthy that Müllen et al. recently reported the first example of direct bromination and oxidation at the K-region of the pyrene without the employment of the sterically tert-butyl groups for utilization in OFETs devices with high hole mobility. ${ }^{16}$

The excellent prospects of the previous examples based on pyrene have motivated researchers to further explore new and facile synthetic routes for the synthesis of pyrene-fused acenes or azaacenes. Bodwell et al. reported a regioselective synthesis of 4,5-dialkoxy-1,8dibromopyrenes with an effectively protective procedure. ${ }^{17}$ Recently, Mateo-Alonso et al. reported an synthetic route for the preparation of 1,3,6,8tetraoctylpyrene-4,5,9,10-tetraone by an indirect method. ${ }^{18}$ Indeed, it is seemingly impossible that both bromination and oxidation of the pyrene is a straightforward and simple method. The main reason is that the solubility of the bromopyrene would decrease as the number of bromine atoms increase. Recently, Müllen et al. reported the latest results on 2,7-dibromo- and diiodo-pyrene-4,5,8,19-tetraones, ${ }^{19}$ however, pyrene has a nodal plane passing through the C2 and C7 carbon atoms in the highest occupied molecular orbital (HOMO) and the lowest unoccupied molecular orbital (LUMO), and thus the substitutions at those positions have less perturbation on the electronic properties of the pyrene core than the substitutions at the active positions of 1-, 3-, 6-, and 8-positions and other positions. ${ }^{20}$ On the assumption that the stable bromopyrene can dissolve in common organic solvents for oxidation, we explored a convenient synthetic route for preparing new pyrene derivatives as promising organic semiconducting materials. Firstly, bromination at the active 1,3-positions of the pyrene afforded the 1,3-dibromo-7-tert-butylpyrene (2), using the tert-butyl group as a protective group. ${ }^{21}$ Compound 2 was then oxidized at the K-region using ruthenium chloride based catalysis ${ }^{13}$ (Scheme 1).

The key intermediate, 1,3-dibromo-7-tert-butylpyrene4,5,9,10-tetraone 3 was easily prepared by the bromination and successive oxidation in considerable yield. Herein, the bulky tert-butyl group in this system could play a significant role, not only in suppressing $\pi-\pi$ stacking interactions and preventing excimer formations, but also in substantially improving the solubility. ${ }^{12}$ Compound $\mathbf{2}$ was chosen because the solubility is considerable, and the symmetrical structure is easy to confirm by ${ }^{1} \mathrm{H}$ NMR following oxidation. The novelty of this system is: 1) This is a feasible example of both bromination at the active sites of 1,3-positions and successive oxidation at the K-region of 4,5,9,10-positions in the pyrene ring using a simple experimental procedure; 
Table 1. Physical and electrochemical properties of compounds 7

\begin{tabular}{|c|c|c|c|c|c|c|c|c|}
\hline & $\begin{array}{l}\lambda_{a b s}{ }^{a} \\
\mathrm{~nm}\end{array}$ & $\begin{array}{c}\lambda_{a b s}^{b} \\
\mathrm{~nm}\end{array}$ & $\begin{array}{c}\lambda_{\text {edge }} \\
\mathrm{nm}\end{array}$ & $\begin{array}{c}E_{\text {HOMO }(\mathrm{CV})^{c}} \\
\mathrm{eV}\end{array}$ & $\begin{array}{c}E_{g a p(o p t)}{ }^{d} \\
\mathrm{eV}\end{array}$ & $\begin{array}{c}E_{H O M O(\mathrm{cal})^{e}} \\
\mathrm{eV}\end{array}$ & $\begin{array}{c}E_{g a p(\text { calcd })^{e}} \\
\mathrm{eV}\end{array}$ & $\begin{array}{l}T_{d}^{f} \\
{ }^{\circ} \mathrm{C}\end{array}$ \\
\hline $7 a$ & 397,419 & 409,424 & 442 & -5.86 & 2.80 & -5.71 & 3.51 & 416 \\
\hline $7 \mathbf{b}$ & 405 & 410 & 455 & -5.72 & 2.72 & -5.33 & 3.18 & 435 \\
\hline 7c & 395,418 & 408,424 & 435 & -6.02 & 2.85 & -6.04 & 3.56 & 391 \\
\hline
\end{tabular}

${ }^{a}$ Measured in $\mathrm{CH}_{2} \mathrm{Cl}_{2} \cdot{ }^{b}$ Measured in a film. ${ }^{c} \mathrm{CV}$ measured in $0.1 \mathrm{M} \mathrm{Bu}_{4} \mathrm{NClO}_{4} / \mathrm{DCM}$ with a scan rate of $100 \mathrm{mV} \mathrm{s}^{-1}$ and the values are calculated using the HOMO levels of ferrocene from the empirical formula: HOMO $=-\left(4.8+E_{\mathrm{ox}}{ }^{\text {onset }}-\mathrm{E}_{\mathrm{ox}}(\mathrm{Fc}){ }^{\text {onset }}\right){ }^{d}{ }^{d} \mathrm{Calculated} \mathrm{from} \lambda_{\text {edge. }}{ }^{e} \mathrm{DFT} / \mathrm{B} 3 \mathrm{LYP} / 6-31 \mathrm{G}^{*}$ using Gaussian. ${ }^{f}$ Obtained from TGA analysis.

2) The active sites at the 1,3-positions can yield Cfunctionalized the pyrene by Suzuki/Sonogashira crosscoupling reactions, thereby avoiding the $\pi$-aggregations; and 3) The K-region of 4,5,9,10-positions can offer an effective strategy to expand the $\pi$-conjugations for pyrene-fused N-PAHs via condensation reactions. Using 3 as a starting material, compounds 7 were synthesized by classical methods in two steps (condensation reaction of $\mathbf{3}$ with 1,2-diamine to afford 4 (83\%) and Suzuki crosscoupling reaction of $\mathbf{4}$ with $p$-substituted phenylboronic acids gave $\mathbf{7}$ in good yields, Scheme 1). As a comparison, we also followed the Mateo-Alonso strategy, ${ }^{18}$ i.e. oxidation of 7-tert-butyl-1,3-dimethoxyphenyl-pyrene (5) afforded the tetraketone 6 (28\%), and then reacted with the 1,2-diamine in acetic acid solution yielded $\mathbf{7 b}(80 \%)$. All synthesized pyrene-fused azaacenes $\mathbf{7}$ possessed good solubility in common organic solvents, and exhibited high decomposition temperatures $\left(T_{\mathrm{d}}\right)$ of up to $416{ }^{\circ} \mathrm{C}$ for $\mathbf{7 a}$, $435{ }^{\circ} \mathrm{C}$ for $\mathbf{7 b}$ and $391{ }^{\circ} \mathrm{C}$ for $\mathbf{7 c}$, which are much higher than those of reported n-acence analogues $(5<\mathrm{n}<7)$; $^{22}$ this is thought to be due to the $-\mathrm{C}=\mathrm{N}-$ in the molecular framework that contributes to enhanced thermal stability.

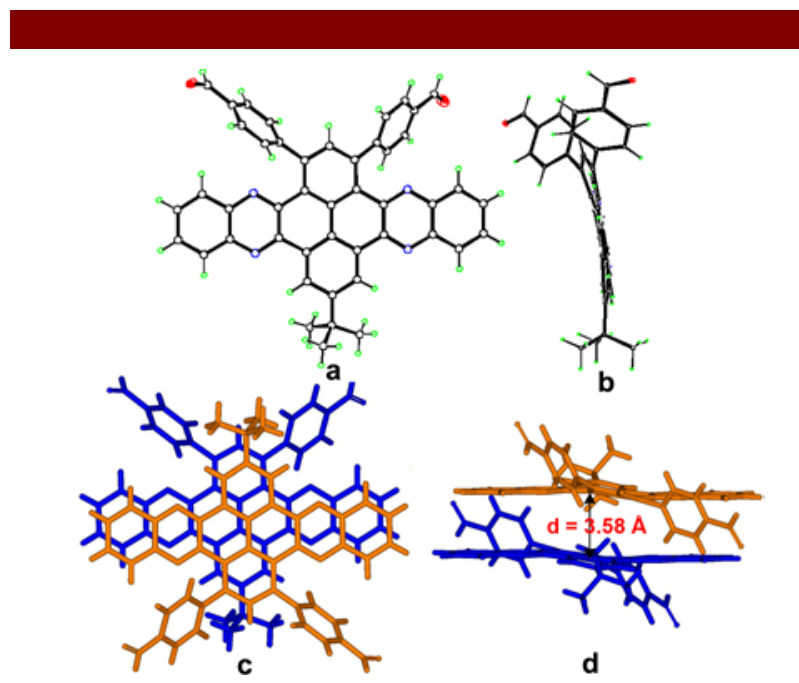

Figure 1. X-ray structure of pyrene-fused azaacene 7c: (a) top view, (b) side view, (c) face-to-face $\pi-\pi$ stacking (top view) and d) side view.

A single crystal of 7c (CCDC 923414) suitable for Xray diffraction studies was obtained from a mixture of $\mathrm{CH}_{2} \mathrm{Cl}_{2}$ and hexane (1:1). The structure is shown in Figure 1. Analysis of the packing reveals that a linear, azaacene unit is arranged in a trapezoid-type alignment with faceto-face $\pi$ - $\pi$ stacking $(\mathrm{d}=3.58 \AA)$. The distance is longer than the value ( $\left(\mathrm{l}=3.48 \AA\right.$ ) reported by Wang et al., ${ }^{15}$ and is attributed to both the tert-butyl group at the 7-position and the terminal formylphenyl moieties located at active sites of 1,3-positions, which prevent the close approach of neighboring pyrene molecules. The twist angles (57.50(4) $\& 53.27(5)^{\circ}$ ) between the formylphenyl groups and the pyrene core are larger than our recent reported value $\left(43.6^{\circ}\right){ }^{21 \mathrm{~b}}$ This is explained in terms of a steric hindrance effect controlling the $\pi-\pi$ stacking interactions. Clearly, the distance associated with the $\pi-\pi$ stacking interactions would be altered though introduction of bulky moieties at the 1,3-sites of pyrene for optical material applications.

As shown in Figure 2, as for the diphenylquinoxalines, ${ }^{23}$ all pyrene-fused azaacenes 7 exhibited well-resolved spectra with clear vibronic structures in the near UV and visible region; the short wavelength of $300-350 \mathrm{~nm}$ was consistent with the $\pi-\pi^{*}$ transitions and the longer wavelength of $375-450 \mathrm{~nm}$ was attributed to the $\mathrm{n}-\pi^{*}$ transitions with less intensity than that of the former. The lowest energy bands of 7 range from 391$420 \mathrm{~nm}$, with molar absorption coefficient of $2.00 \times 10^{-4}$, $5.91 \times 10^{-4}$ and $2.62 \times 10^{-4} \mathrm{~mol}^{-1} \mathrm{~cm}^{-1} \mathrm{~L}$. The optical band gaps were estimated from UV absorption at $2.80 \mathrm{eV}$ for 7a, $2.72 \mathrm{eV}$ for $\mathbf{7 b}$ and $2.85 \mathrm{eV}$ for $\mathbf{7 c}$, respectively.

Due to rigid profiles azaacenes 7 contain the same $\pi$ conjugated pyrene-azaacenes fragments but in the relative position with different terminal substitutions, which showed indistinctive absorption spectra both in $\mathrm{CH}_{2} \mathrm{Cl}_{2}$ solutions and in the solid state. Although the exact aggregation behavior of $\mathbf{7}$ in thin film is not clear from the absorption spectra, bathochromic shifts $(\leq 10 \mathrm{~nm})$ were observed arising from intermolecular interactions.

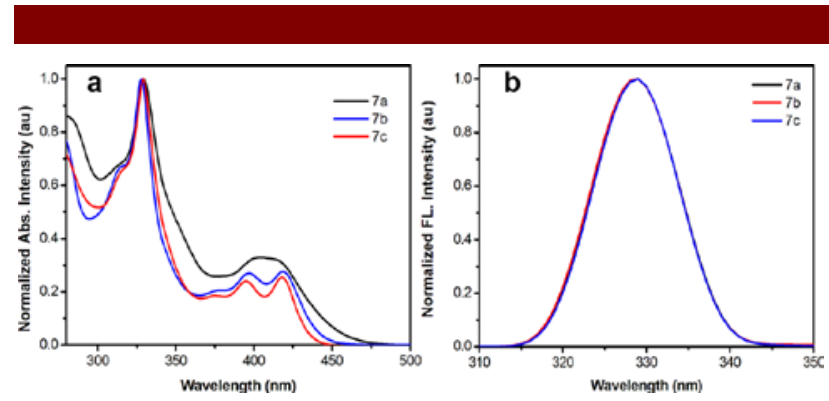

Figure 2. UV-Vis absorption spectra of 7: (a) in $\mathrm{CH}_{2} \mathrm{Cl}_{2}$ solution and (b) in a film. 
The redox behaviors of 7 were investigated in $\mathrm{CH}_{2} \mathrm{Cl}_{2}$ solution by cyclic voltammetry (CV) (see Supporting Information). Electrochemical irreversible redox waves were observed for 7 , the highest occupied molecular orbital (HOMO) energy levels derived from the onset of oxidation potentials are $-5.86 \mathrm{eV}$ for $\mathbf{7 a},-5.72 \mathrm{eV}$ for $\mathbf{7 b}$ and $-6.02 \mathrm{eV}$ for 7c. It is noteworthy that the electronwithdrawing nature of the - $\mathrm{CHO}$ group had a remarkable effect on the redox properties of these azaacenes. The presence of the -CHO moiety is beneficial in terms of increasing the $\pi$-conjugation of the entire molecular structure, and leads to a lower HOMO level.

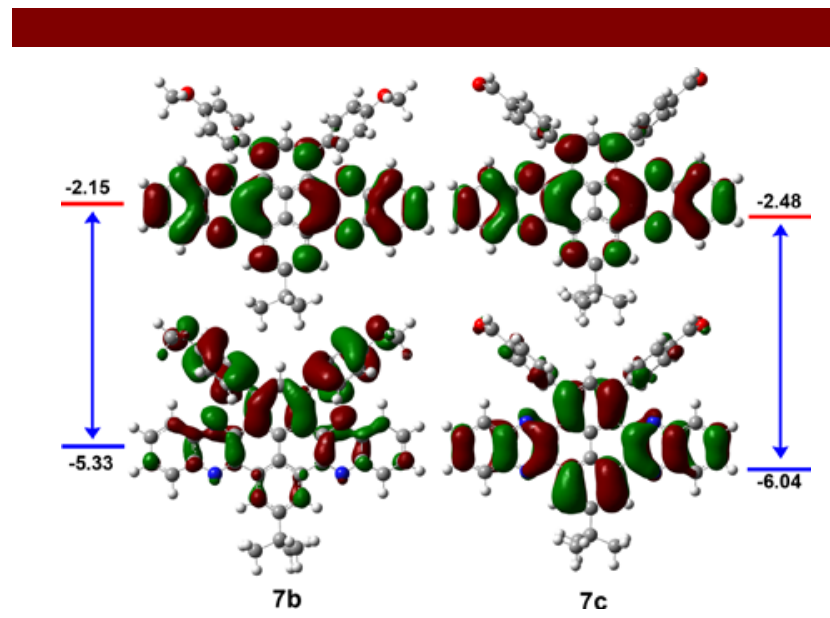

Figure 3. Computed molecular orbital plots (B3LYP/6-31G*) of 7, up for LUMOs and down for HOMOs.

The geometries and electronic structures associated with 7 were evaluated by the density functional theory (DFT; B3LYP/6-31G*), the HOMO-LUMO gaps (3.51 $\mathrm{eV}$ for $\mathbf{7 a}, 3.18 \mathrm{eV}$ for $\mathbf{7 b}, 3.56 \mathrm{eV}$ for $\mathbf{7 c}$ ) are in consistent with the experimental observations. As expected, the LUMO of 7 were mostly located on the azaacene core, however, it is notable that the HOMO of 7 were significantly different, in that they spread from mainly terminal methoxyphenyl groups and partially the pyrene core in $\mathbf{7 b}$, to the entire pyrene-azaacene molecular framework in 7a, and just to the azaacene core in 7c (Figure 3 and SI), indicating that the electrondonating/accepting groups located at the para-positions could significantly influence the HOMO distributions by conjugating with the pyrene core in these azaacene systems.

In summary, a novel synthetic route to new pyrenefused azaacenes 7 was explored starting from the 1,3dibromo-7-tert-butylpyrene-4,5,9,10-tetraone, which is the first example of both bromination at the active sites (1,3-positions) and oxidation at the K-region (4,5,9,10positions) of the pyrene. All these pyrene-fused azaacenes 7 exhibited good solubility and high stabilities. The experimental (crystal packing, UV/Vis, and CV) and theoretical (DFT calculations) results indicated that these azaacenes might be promising candidates for n-type organic semiconductors. This work offers an available/facile method to functionalize the pyrene core at six positions $(1,3,4,5,9,10-)$ and provides a strategy to prepare new pyrene-fused azaacenes.

Acknowledgment This work was performed under the Cooperative Research Program of "Network Joint Research Center for Materials and Devices (Institute for Materials Chemistry and Engineering, Kyushu University)". We would like to thank to the International Collaborative Project Fund of Guizhou province at Guizhou University for financial support. We also would like to thank the EPSRC (overseas travel grant to C.R.) and The Royal Society for financial support.

Supporting Information Available Details of experimental procedures, ${ }^{1} \mathrm{H} /{ }^{13} \mathrm{C}$ NMR spectra, X-ray crystallographic data, photophysical data, TGA analysis and computational plot. This materials is available free of charge via the Internet at http://pubs.acs.org.

1 Electronics Materials: The Oligomer Approach; Müllen, K.; Wegner, G.; Eds.; Wiley VCH: Weinheim, Germany, 1998.

2 Wang, C.-L.; Dong, H.-L.; Hu, W.-P.; Liu, Y.-Q.; Zhu, D.-B. Chem. Rev. 2012, 112, 2208-2267.

3 Duong, H. M.; Bendikov, M.; Steiger, D.; Zhang, Q.-C.; Sonmez, G.; Yamada, J.; Wudl, F. Org. Lett. 2003, 5, 4433-4436.

4 Chun, D.; Cheng, Y. and Wudl, F. Angew. Chem. Int. Ed. 2008, 47, 8380-8385.

5 Biermann, D.; Schmidt, W. J. J. Am. Chem. Soc. 1980, 102, 31633173.

6 Gierschner, J.; Cornil, J.; Egelhaaf, H.-J. Adv. Mater. 2007, 19, 173-191.

7 Xu, Q. F.; Duong, H. M.; Wudl, F.; Yang, Y. Appl. Phys. Lett 2004, 85, 3357-3359.

8 More, S.; Bhosale, R.; Choudhary, S.; Mateo-Alonso, A. Org. Lett. 2012, 14, 4170-4173.

9 Winkler, M.; Houk, K. N. J. Am. Chem. Soc., 2007, 129, 18051815.

10 (a) Figueira-Duarte, T. M.; Müllen, K. Chem. Rev. 2011, 111, 7260-7314. (b) Hu, J.-Y.; Pu, Y.-J.; Nakata, G.; Kawata, S.; Sasabe, H.; Kido, J. Chem. Commun., 2012, 48, 8434-8436.

11 Feng, X.; Hu, J.-Y.; Iwanaga, F.; Seto, N.; Redshaw, C.; Elsegood, M. R. J.; Yamao, T. Org. Lett. 2013, 15, 1318-1321.

12 (a) Hu, J.-Y.; Era, M.; Elsegood, M. R. J.; Yamao, T. Eur. J. Org. Chem. 2010, 72-79. (b) Hu, J.-Y.; Feng, X.; Seto, N.; Do, J.-H.; Zeng, X.; Tao, Z.; Yamao, T. J. Mol. Struct. 2013, 1035, 19-26.

13 Hu, J.; Zhang, D.; Harris, F. W. J. Org. Chem. 2005, 70, 707-708.

14 Fogel, Y.; Zhi, L.-J.; Rouhanipour, A.; Andrienko, D.; Räder, H. J.; Müllen, K. Macromolecules 2009, 42, 6878-6884.

15 Gao, B.-X.; Wang, M.; Cheng, Y.-X.; Wang, L.-X.; Jing, X.-B.; Wang, F.-S. J. Am. Chem. Soc. 2008, 130, 8297-8306.

16 (a) Zöphel, L.; Beckmann, D.; Enkelmann, V.; Chercka, D.; Rieger, R.; Müllen, K. Chem. Commun. 2011, 47, 6960-6962. (b) Zöphel, L.; Enkelmann, V.; Müllen, K. Org. Lett., 2013, 15, 804-807.

17 Venkataramana, G., Dongare, P., Dawe, L. N., Thompson, D. W., Zhao, Y., Bodwell, G. J. Org. Lett. 2011, 13, 2240-2243.

18 Kulisic, N.; Moreab, S.; Mateo-Alonso, A. Chem. Commun. 2011, 47, 514-516.

19 Kawano, S.-i.; Baumgarten, M.; Chercka, D.; Engkelmann, V.; Müllen, K. Chem. Commun. 2013, 49, 5058-5060.

20 (a) Crawford, A. G.; Dwyer, A. D.; Liu, Z-Q.; Steffen, A.; Beeby, A.; Pålsson, L.-O.; Tozer, D. L.; Marder, T. B. J. Am. Chem. Soc., 2011, 133, 13349-13362. (b) Crawford, A. G.; Liu, Z.-Q.; Mkhalid, I. A. I.; Thibault, M-H.; Schwarz, N.; Alcaraz, G.; Steffen, A.; Collings, J. C.; Batsanov, A. S.; Howard, J. A. K.; Marder, T. B. Chem.-Eur. J. 2012, 18, 5022-5035.

21 (a) Figueira-Duarte, T. M.; Simon, S. C.; Wagner, M.; Druzhinin, S. I.; Zachariasse, K. A.; Müllen, K. Angew. Chem. Int. Ed. 2008, 47, 10175-10178. (b) Feng, X.; Hu, J.-Y.; Yi, L.; Seto, N.; Tao, Z.; Redshaw, C.; Elsegood, M. R. J.; Yamato, T. Chem.-Asian J. 2012, 7, 2854-2863.

22 Mochida, K.; Kawasumi, K.; Segawa, Y.; Itami, K. J. Am. Chem. Soc., 2011, 133, 10716-10719.

23 Li, S.-R.; Lee, C.-P.; Kuo, H.-T.; Ho, K.-C.; Sun, S.-S. Chem.-Eur. J. 2012, 18, 12085-12095 